\title{
El ideal y lo posible. Las reformas tucumanas en la construcción del estado provincial (1820-1852)
}

\author{
The ideal and the possible. Tucuman reforms in the construction of the \\ provincial state (1820-1852)
}

\author{
Facundo Nanni \\ facundosnanni@yahoo.com.ar \\ Universidad Nacional de Tucumán, Argentina. \\ Universidad San Pablo-Tucumán. Junta de Estudios \\ Históricos de Tucumán, Argentina \\ Ana Cristina Wilde \\ anitawilde@yahoo.com \\ Instituto de Estudios Críticos en Humanidades. \\ Universidad Nacional de Rosario-CONICET, \\ Argentina \\ Instituto de Investigaciones Históricas Dr. Ramón \\ Leoni Pinto. Facultad de Filosofía y Letras. \\ Universidad Nacional de Tucumán, Argentina
}

Recepción: 17 Marzo 2021

Aprobación: 26 Mayo 2021

Publicación: 01 Julio 2021

Cita sugerida: Nanni, F. y Wilde, A. C. (2021). El ideal y lo posible. Las reformas tucumanas en la construcción del estado provincial (1820-1852). Trabajos y Comunicaciones, (54), e155. https://doi.org/10.24215/23468971e155

\begin{abstract}
Resumen: Al caer el gobierno central en 1820, las ciudadesprovincias tuvieron que resolver la herencia colonial y los cambios iniciados por la Revolución. En este artículo abordamos la creación y/o reforma de las principales instituciones y prácticas políticas emprendidas con el fin de alcanzar la gobernabilidad del territorio de Tucumán. Desde la bibliografía especializada y a partir de nuestras propias investigaciones analizamos el desenvolvimiento del gobernador, la emergencia de la legislatura, la reorganización de la justicia, milicias y policía, como así también, la politización del espacio público. Estas variables revelaron un orden republicano sincrético entre lo nuevo y lo viejo, en donde la apelación constante a la "emergencia" fortaleció al gobernador y antepuso el orden común a los derechos y garantías individuales.
\end{abstract}

Palabras clave: Reformas, Provincias, Orden Republicano, Herencia Colonial.

Abstract: When the central government was dissolved in 1820 , the city-provinces had to resolve the colonial heritage and the changes initiated by the Revolution. In this article we analyze the creation or reform of certain institutions and political practices undertaken in order to achieve the governance of the territory of Tucumán. From the specialized bibliography and our own investigations we examine the development of the governor, the emergence of the legislature, the reorganization of justice, militias and police, as well as the politicization of public space. These variables revealed a syncretic republican order between the new and the old, where the constant appeal to "emergency" strengthened the governor and put the common order before individual rights and guarantees.

Keywords: Reforms, Provinces, Republican Order, Colonial Heritage.

Luego de la caída del gobierno central a comienzos de 1820, las ciudades-provincias quedaron libradas a sus propias fuerzas para resolver la herencia colonial y las transformaciones de diez años de revolución y guerra. A partir de entonces, sus trayectorias registraron algunas constantes: la extinción de Cabildos, la 
creación de Salas o Juntas de Representantes y la consolidación de la opción republicana de gobierno. Aparecieron un conjunto de constituciones provinciales basadas en el principio de la representación política moderna y en el concepto de ciudadanía, si bien tuvieron varias marcas de continuidad con lo antiguo. Tucumán no fue la excepción, aunque su experiencia constitucional fue efímera.

La provincia emprendió una construcción política-institucional orientada por los principios liberales de la revolución que, si bien tuvieron dispar impacto en las prácticas concretas de la primera mitad del siglo XIX, concurrieron a formar una república en donde los ciudadanos elegían a sus representantes y tenían derechos novedosos como el acceso al voto o a elegir un defensor en instancia judicial; los gobernantes ganaban estabilidad e institucionalidad; la justicia cobraba efectividad y la campaña se volvía más ordenada. Se trató de una república sincrética entre lo nuevo y lo viejo (Tío Vallejo, 2001 y Zamora, 2019), extraordinaria y de transición antes que liberal. No obstante, fue una república con gobiernos conforme a la ley, avalados por un sistema representativo de base ampliada y que -muy progresivamente y con contramarchas- fue ganando estabilidad.

En estas páginas reflejamos una síntesis de algunas aristas de la construcción institucional que se llevó a cabo en Tucumán entre 1820 y 1852, a partir del análisis de la bibliografía especializada y del aporte de nuestras propias líneas de investigación. Consideraremos los insumos constitucionales que sirvieron de base a los ensayos políticos del período, la formación de la Legislatura, la evolución del gobernador provincial y las principales instituciones de gobernabilidad: justicia, milicia y policía. También indagaremos en los cambios que la ruptura con España y la experiencia de guerra y autogobierno promovieron en la esfera de lo público.

\section{UN GobIERNo SIN CABILDO}

\section{I.a. La República de Tucumán y sus bases constitucionales}

La caída del gobierno central posibilitó en Tucumán una serie de modificaciones. Es interesante notar el fuerte rol que tuvo el Cabildo en este momento de innovación, aun cuando luego fue disuelto en el marco de las reformas que acompañó. El ayuntamiento tucumano fue de hecho clave en el contexto de la invitación del gobernador de Córdoba, en febrero de 1820, para que Tucumán participe de un Congreso que pronto se vería deslegitimado. En respuesta al gobernador Juan Bautista Bustos, el Cabildo tucumano actuó en conjunto con el gobernador Bernabé Aráoz, desplegando una retórica que contenía un principio autonomista luego plasmado con la instalación de la República de Tucumán. En un juego de aproximaciones con Bustos, los cabildantes tucumanos acordaron con él la necesidad de un Congreso, pero en caso de no ser posible, afirmaron que Tucumán se reservaba el derecho de "fijar su destino", así como de "consultar su felicidad sin desatender los intereses generales de la Patria”" (Lizondo Borda, 1940, II, pp. 219-220).

En el mismo febrero de 1820 se convocó a los pueblos de Santiago y Catamarca a un Congreso Provincial del cual surgiría la República de Tucumán. En este juego de alternativas de Congresos, teniendo en cuenta que además de la oferta de Bustos pronto el Tratado del Pilar propondría uno en San Lorenzo, la elite local apostó al control sobre aquellos pueblos nucleados en Tucumán desde su creación provincial en 1814. La República de Tucumán fue un intento de nueva organización para una entidad política ya existente. Sin embargo, en las semanas posteriores a la convocatoria del Congreso Provincial se precipitaron incidentes en Santiago. A las tropas enviadas por Bernabé Aráoz para asegurar que el Cabildo santiagueño eligiera diputados afines, se le añadió una agresiva propaganda de proclamas acusando que el pueblo subordinado "se deslumbra y alucina con la ilusión de formar un gobierno federal, sin advertir su minoridad e impotencia” (Nanni, 2016). En abril de 1820 Santiago proclamó su autonomía y el comandante de la frontera de Abipones, Juan Felipe Ibarra, se erigió como referente del norte durante tres décadas reordenando, a partir de su alianza con Martín Miguel de Güemes, el equilibrio en el norte. 
En cuanto a las autoridades de Catamarca, que advirtieron el fracaso de Aráoz en subordinar a Santiago, aceptaron el envío de diputados, pero poco después iniciaron un camino de autonomía concretado en agosto de 1821. Aún sin Santiago, la actividad constituyente de mayo a septiembre de 1820 fue crucial. La Constitución que se sancionó ese año fue un hito breve pero fundamental: primera experiencia constitucional, primer antecedente de supresión del Cabildo, primera puesta en marcha de una división republicana de poderes inspirada en la Constitución de 1819. Consolidó la tendencia a la institucionalización de las potestades de gobierno y de formación de un "estado provincial" en el sentido en que lo expone Chiaramonte (1995). La voluntad de unión con las provincias y el apoyo en pactos como pronto ocurrió en Vinará (1821) indican que la voz "República" tuvo plurívoco sentido en la ley de leyes tucumana, intercambiando por "Provincia" en diferentes pasajes del texto, a modo de sinónimo. La Constitución de 1820 pretendió un punto de frágil equilibrio entre una república con autonomía y la vinculación al espacio rioplatense: "Tucumán es ya, y será a toda costa, una república libre e independiente, hermana sí y federada con vínculos tan estrechos que jamás se dispensará sacrificio alguno, hasta no ver a sus pies rotos (...) los últimos eslabones (...) que subyugan a la más pequeña" (Celesia, 1930). ${ }^{1}$

Como texto constitucional, el de 1820 debe observarse en función del contexto local y rioplatense, pero también a la vista del crecimiento del constitucionalismo liberal a nivel atlántico. En el escenario local, se vincula con el poder de los Aráoz y con el movimiento de armas que había repuesto a Don Bernabé un año atrás; por esta razón, la historiografía tradicional tucumana ubica "el punto inicial de la autonomía" el 11 de noviembre de 1819 (Terán, 1910, p. 22). Pese a su equivalencia con "Provincia”, el concepto "República" aludía también a aspectos orgánicos de la Constitución: división en poderes, periodicidad de los mandatos, principio de soberanía popular, elecciones, libertades individuales. Asimismo, en su pretensión de incluir a diferentes pueblos recuerda a la simultánea República de Entre Ríos (1820-1821) que pretendió integrar a Corrientes, aunque ésta última se desmembraría en 1821, dictando su propia Constitución provincial.

En la flamante Constitución tucumana, el poder ejecutivo recaía en el Presidente Supremo, con mandato de 4 años y posibilidad de una reelección inmediata. Designado por el Congreso Provincial conforme a una idea de equilibrio de poderes, sus atribuciones eran vigorosas: jefe militar de la provincia, con capacidad para celebrar pactos y acuerdos, remover y nombrar ministros. Por su parte, el Poder Legislativo estaba compuesto por el Congreso Provincial, era unicameral, formado por 2 diputados de origen civil y uno eclesiástico y sus funciones consistían en la sanción de leyes, la regulación del comercio y la fijación de monedas. La Constitución reconvirtió al Cabildo en Corte Primera de Justicia que, además de atribuciones judiciales, participaba en casi todas las instancias de elección de órganos de gobierno excepto en el Legislativo. Es decir, el Cabildo había dejado de existir en la breve república constitucional tucumana, pero su representación estamental sobrevivió. ${ }^{2}$ El Poder Judicial se completaba con una Alta Corte de Justicia, compuesta por 3 jueces y un fiscal escogidos por el Congreso. Por fuera de los aspectos orgánicos vinculados a los poderes, se observa la vigencia del peso normativo de la religión, en correspondencia con la tradición jurídica hispánica. La Carta protegía la religión católica apostólica romana, única permitida en la provincia, lo cual fue frecuente en otras constituciones rioplatenses salvo la notable excepción de la de San Juan, de 1825, que se pronuncia a favor de la tolerancia religiosa. El texto tucumano, en cambio, en la sección dedicada a los derechos particulares (libertad, seguridad, propiedad y vida), reconoce la libertad de prensa, pero la suspende en lo referido a temas religiosos.

La Constitución de 1820 no implicó la desaparición del Reglamento de 1817, por el contrario, se mantuvo vigente en todos los aspectos no reglados por esta Carta, y continuó rigiendo una vez extinguida la experiencia política de Bernabé Aráoz (Tío Vallejo, 2008). ${ }^{3}$ Si bien la República de Tucumán marcó un punto sugerente en las reformas institucionales de la provincia, veremos que no fue suficiente para paliar las dificultades que la gestación del orden republicano reportó a la jurisdicción. 


\section{I.b. El poder ejecutivo y legislativo. Un juego de delimitaciones mutuas}

Desde la década de 1820 la designación de los gobernadores tucumanos comenzó a realizarse a partir de procesos electivos llevados a cabo por la Legislatura. Durante este período, en todas las provincias la Sala escogía al gobernador, a excepción de Corrientes en donde el Reglamento de 1821 estipulaba la creación de una asamblea electoral. El Estatuto santafesino de 1819 establecía el voto directo de los ciudadanos, pero la atribución quedó finalmente en manos legislativas (Tau Anzoátegui y Martiré, 2005). Sin embargo, el ideal republicano de cumplimiento de los mandatos y alternancia en el poder parecía una quimera en Tucumán. Por ejemplo, el año 1822 recibió el mote de "año clásico de la anarquía” por parte de la historiografía clásica provincial por la sucesión de 11 gobernadores tan sólo en ese lapso de tiempo (Terán, 1910, p. 37).

Más allá de la singularidad de aquellos meses de cruces entre Bernabé Aráoz y dos de sus antiguos aliados (Javier López y Diego Aráoz), durante la primera mitad del siglo XIX, los mandatarios tucumanos no solían completar su período legal de 2 años en el poder y, cuando lo hacían, el principio de alternancia no se respetaba porque las Legislaturas los reeligían sucesivamente, como ocurrió con Alejandro Heredia (1832-1838) y Celedonio Gutiérrez (1841-1852). La ambivalencia entre estas dos situaciones fue un rasgo que la Carta de 1854 intentó resolver (Bravo y Ferullo, 2017). Sin embargo, como veremos, el problema se había abordado antes, en el debate constitucional inconcluso de 1835.

Amén de la inestabilidad política, los años veinte se destacaron por la emergencia del ámbito legislativo: depositario de la soberanía provincial, pilar de gobernabilidad junto al ejecutivo -del cual, además, era su contrapeso-, e institución emblemática del desmantelamiento de instituciones coloniales.

En 1824, la Sala suprime definitivamente al Cabildo. En las fuentes, no hay rastros de que esto haya generado ningún debate. ${ }^{4}$ Coincidimos con la historiografía en que la institución colonial se desarmó en un marco de crecimiento del lenguaje republicano (Nanni, 2011), de ascenso del principio de representación política individual y moderna y de superposición de funciones entre Cabildo y la Legislatura. En este contexto, y siendo tan arraigada la representación territorial provincial que detentaba el cuerpo capitular, su reconversión en órgano de gobierno limitado a ciudad y a tareas de policía no parecía posible. Quizás -como parece probado en el caso porteño-, la memoria de la sociedad entre los cabildos abiertos y jefes militares en asonadas recientes también tuvieron que ver en aquella decisión sin discusión de su abolición en Tucumán. Por otro lado, la notabilidad de la provincia que se había afianzado en torno al cabildo ya en la época de las reformas borbónicas, encontró nueva expresión en la Sala de Representantes y esa doble representación, que sólo se vivió por unos años, pudo revelar como inconveniente la pervivencia de la institución colonial habida cuenta de la exigüidad de la elite y la escasez del fisco, dos rasgos siempre presentes en las fuentes (Tío Vallejo, 2001 y 2014). ${ }^{5}$

La Sala de Representantes, por su lado, tenía un fuerte y directo antecedente en las Juntas Electorales, en tanto vehiculizaba la soberanía popular y era responsable de la designación del gobernador. Muñida de este nuevo principio de representación política, la legislatura terminó desplazando al Cabildo, de cuyo desmantelamiento también se benefició el gobernador (Tío Vallejo, 2001).

Por su parte, la experiencia del sufragio fue clave para movilizar jerarquías sociales, en paralelo al desarrollo de la militarización. Se ensanchó el universo de votantes y se consolidó la participación política de la población a través de la doble vía legada por la revolución: las elecciones y las armas (Tío Vallejo, 2001). Desde la década de 1810 se aceleró el pasaje de la vecindad a la ciudadanía, más allá de hibridaciones y confluencias entre ambos conceptos. Los actos electivos se apoyaron en disposiciones cambiantes que luego fueron reemplazadas por un reglamento provincial elaborado en $1826 .{ }^{6}$ Esta normativa establecía -como otras leyes similares en el Río de la Plata-, que podía votar todo hombre libre natural del país o avecindado en él con oficio útil y lucrativo o que tenga una propiedad conocida desde la edad de 20 años (Coviello, 1938, I, pp. 282-285). La ley, pero sobre todo el modo en que fue puesta en práctica, estableció una base electoral muy amplia, especialmente 
si la contrastamos con el sufragio existente en el resto del espacio atlántico, ya que el criterio de propiedad u oficio que menciona este reglamento no suponía un límite censitario a la ciudadanía sino una garantía del arraigo en la comunidad (Abbate, 2017).

La historiografía ha distinguido etapas en la Sala en función de su relación con el ejecutivo y el contexto político (Nanni, 2011). La primera, entre 1822 y 1825, estuvo signada por la fragilidad de la Legislatura, pero también por su reglamentación inicial que posibilitó su posterior consolidación. La segunda fase (1825-1826) se caracteriza por la fuerte vocación de garante de la institucionalidad provincial que desplegó este cuerpo cuando, por ejemplo, emprendió juicio político a Gregorio Aráoz de Lamadrid por su acceso violento al poder. En la tercera etapa (1827-1831), la Sala aparece desdibujada por la gran inestabilidad que produjeron las invasiones de Facundo Quiroga a la provincia. El cuarto período (1833-1852) coincide con los largos gobiernos federales de Alejandro Heredia y Celedonio Gutiérrez. El primer año de este ciclo fue de reorganización dado que la Legislatura había estado inactiva desde 1831. Después se dieron dos años de interesante interacción con el ejecutivo, pero luego comenzó a perder peso frente al avance de las facultades otorgadas al gobernador.

Retomando el inicio de la Sala, en 1822, cabe recordar que en ese año hubo 11 recambios de gobierno. La primera Sala, instituida en febrero de 1822 con 8 diputados, duró solo hasta mayo. Los argumentos de su disolución fueron la falta de "orden y paz" en la provincia y que no lograba completar su número legal de miembros. Renuncias, ausencias y largos paréntesis signaron la participación de muchos diputados de esta novel institución, fenómenos que sumados al carácter honorífico del cargo dan cuenta de la lenta especialización del campo político.

Por su parte, el nuevo poder ejecutivo provincial contaba con los antecedentes del gobernador intendente de la época borbónica y las disposiciones del Reglamento de 1817. Fortaleció su campo de acción el contexto de autonomía provincial y el desmantelamiento del Cabildo, cuyas funciones de administración y policía pasaron a su cargo. Entre 1822 y 1825, las figuras políticas de mayor peso fueron Bernabé Aráoz, que terminaría fusilado en 1824, y dos antiguos partidarios suyos: Diego Aráoz y Javier López. El constante vaivén de alianzas entre estos protagonistas y sus seguidores apenas se apaciguaba por breves periodos de tregua en los que solían asumir gobernadores de perfil comerciante o letrado. Pero cuando los ejecutivos no tenían un perfil militar, difícilmente lograban cumplir su mandato. Por ejemplo, el gobernador Nicolás Laguna, abogado, finalmente logró abandonar su cargo a principios de 1824, tras sólo dos meses de asumir, y a pesar de las negativas de la legislatura en aceptar su dimisión. (Coviello, 1938, I, p. 64) Había estado asediado por las fuerzas de Javier López, su Comandante de Armas. El poder ejecutivo ganará mayor estabilidad en las décadas de 1830 y 1840 a partir de las reformas de las milicias y de la reorganización de la justicia, como veremos luego.

El joven López, que se había formado criando caballos en el entorno de los Aráoz, intentó estabilizar la legislatura hacia 1823 dotándola de una reglamentación influida por la de Buenos Aires. En su caso, las veces que fue gobernador, su permanente juego de renuncias y aceptaciones del cargo no nacían del asedio militar -variable que dominaba relativamente-, sino de una estrategia de fortalecimiento en el poder. Objetivo en el que tuvo éxito: la legislatura decidió retenerlo para evitar el regreso de los "perturbadores del orden", conjurando una posible vuelta de Bernabé Aráoz.(Coviello, 1938, I, pp. 25-26)

Pese a los altos niveles de conflictividad, la década de 1820 fue testigo del primer despliegue institucional republicano en la jurisdicción de Tucumán, destacándose la interacción entre el ejecutivo y el legislativo. Un interesante mirador de esta relación lo constituye la presencia del ejecutivo en la legislatura a través de las visitas de su ministro al recinto, tal como ocurría en otras provincias; presencia no exenta de fricciones. El ejercicio deliberativo y la oratoria eran capitales específicos (Ternavasio, 2004) que surgían en las provincias en este proceso de mutua articulación entre la Sala y el primer magistrado. ${ }^{7}$ Desde la década de 1820 se impuso en la provincia la práctica de los mensajes del gobernador a la Sala realizados al concluir su mandato. Esta acción, además de responder al principio republicano de publicidad de los actos de gobierno, tendía puentes entre el gobierno y la legislatura, que respondía de manera protocolizada, a menudo con elogios a 
la gestión saliente. A su vez, la asistencia del público en la barra reforzaba la idea de soberanía y la relación representantes/representados.

Si la primera etapa de la Legislatura fue de inicio accidentado, la segunda fase (1825-1826) señaló un efímero pero significativo fortalecimiento, durante el cual actuó con mayor autonomía frente al gobernador. Se destaca un clima republicano más marcado, particularmente visible en el juicio político que los diputados iniciaron a Lamadrid para que defendiera la legitimidad de su golpe de armas contra Javier López. La historiografía mostró que no se trató de una mera formalidad, sino de largos meses de deliberación en donde se distinguieron los diputados de origen religioso por su detallado manejo de las reglamentaciones. El general tucumano se vio obligado a dar largas explicaciones orales desde 1825 y un sólido informe escrito a mediados de 1826. El proceso estuvo orientado a defender la periodicidad de los mandatos y el origen electoral/ institucional del poder.

Durante este período el cuerpo legislativo respondió a favor de la forma unitaria de gobierno a la consulta realizada en 1824 por el Congreso reunido en Buenos Aires. (Coviello, 1938, I, pp. 213-214) Salta, Jujuy y La Rioja respondieron del mismo modo. Fuera del recinto, el clima deliberativo que caracteriza a esta etapa de la Sala, tuvo su correlato en la aparición de periódicos, asociaciones y otras iniciativas que analizaremos en breve. Esta fase supuso, también, un despliegue más claro del poder ejecutivo y sus ministros. Además del Ministro Secretario que se encargaba de asuntos de hacienda y gobierno, se creó el cargo de Asesor Letrado que asistía al gobernador y a los jueces legos en lo judicial y contencioso. ${ }^{8}$

La tercera etapa legislativa (1826 a 1831) se diferencia de la anterior por la pérdida de protagonismo político de la institución a raíz de la situación de emergencia planteada por las tres incursiones de Quiroga. La última de ellas puso fin a la Liga del Interior y a la actividad de la Sala por dos años. No obstante, aun antes de su disolución, el rol de la Sala se había reducido a autorizar empréstitos de guerra y sus sesiones habían perdido capacidad deliberativa (Nanni, 2011).

La cuarta etapa (1833-1852) estuvo marcada por la relativa estabilidad de Alejandro Heredia y Celedonio Gutiérrez en el poder. Heredia, hombre de armas y de letras, dispuso la reinstalación de la Sala con pomposa ceremonia y mantuvo con ella un juego de contrapesos en los primeros años de su gestión. La historiografía muestra álgidas discusiones legislativas entre los años de 1833 y 1834 que incluyen el debate de un nuevo proyecto constitucional que se sigue hasta 1835 , momento en que se interrumpe por un conflicto armado con una provincia vecina. El sobrino de Javier López, Ángel López, y otros comerciantes tucumanos que formaban parte de la Comisión de Hacienda del recinto intentaron primero una resistencia desde el espacio de la Sala, pero siendo impotentes allí, apelaron a la conspiración armada que contó finalmente con apoyos en Salta (Macías, 2014). El gobernador logró un rápido dominio militar de la situación que, tras la recurrencia conspirativa de Ángel López, terminó en su fusilamiento. Este desenlace produjo la sumisión de la Legislatura al primer mandatario. Desde entonces, ésta renovó canónicamente las facultades extraordinarias a Heredia, avaló su proyecto de Protectorado sobre las provincias limítrofes y nunca más retomó el proyecto constitucional que contemplaba, entre otras cosas, la no renovación sucesiva del mismo titular en el Ejecutivo (Terán, 1910; Nanni 2011). El pasaje de la deliberación a la ratificación de la voluntad del gobernador por parte de la Sala se consolidó durante el gutierrismo, que además contaba con el aval externo del gobernador de Buenos Aires, Juan Manuel de Rosas, que entonces alcanzaba su máxima proyección política sobre la Confederación. En este marco, Celedonio Gutiérrez también pudo operar la subordinación del resto de los poderes a su autoridad. 


\section{I.c. Un espacio público en transformación: sociabilidad, circulación de la opinión y liturgia política}

La ciudad de San Miguel de Tucumán, que ya había transformado parte de su fisonomía colonial al albergar al ejército entre 1812 y 1819 , inició un camino de reformas en las décadas siguientes que se reflejaron en la construcción social de un nuevo espacio público.

Uno de los ámbitos de estas transformaciones fue la prensa. El general Belgrano, fiel a su experiencia en Buenos Aires, utilizó durante su larga estadía en Tucumán una imprenta volante para inaugurar en 1817 el Diario Militar del Ejército del Perú, primer periódico local. Fue una acción innovadora para el norte: Salta no tendría imprenta sino hasta 1824 y Catamarca, Jujuy y Santiago lo lograrían recién a mediados de siglo. Bernabé Aráoz la utilizó para intentar controlar la opinión pública de Santiago y Catamarca a través de proclamas breves, para editar el primer periódico netamente político, El Tucumano Imparcial, editado en 1820, y para difundir la Constitución sancionada ese mismo año. Bastante más tarde, se desarrolló una prensa con lemas rosistas, caracterizada por una dura retórica contra el adversario político (El Monitor Federal, editado entre 1842 y 1844 y La Estrella Federal del Norte, publicado durante 1841). En general, estos impresos tuvieron una circulación discontinua y restringida a familias cercanas al poder pero, aun así, dinamizaron la política y vehiculizaron la difusión de los nuevos principios. La presencia del ejército generó otras marcas en el espacio público, como la edificación de la Ciudadela o la Pirámide de Chacabuco de 1817, construcciones duraderas que pretendían conectar al pueblo con los nuevos valores revolucionarios, a modo de pedagogía cívica.

Las leyes acompañaron el incipiente ensanchamiento de la dimensión pública: la Constitución de 1820 establecía la libertad de prensa, aunque fijaba límites en la temática religiosa como la posterior normativa de $1824 .{ }^{9}$ No obstante, el poder normalizador de la religión co-existía en el espacio público junto a la escurridiza circulación de la palabra contestataria (Nanni, 2013). La variedad de sus soportes (impresos, manuscritos, rumores orales) ayudaba a eludir los controles, como así también el anonimato y la nocturnidad. Pasquines criticando el precio del pan, libelos que se animaban a discutir lo religioso y una rica oralidad que transmitía chismes o rumores alteraban la arena pública difundiendo noticias que excedían los recaudos de las comunicaciones oficiales. En 1823, un pasquín escandalizó al Cabildo al denunciar a la pulpería de Mañan por especular con la harina, pero aceptaron que la publicidad del mensaje anónimo era "el único desahogo del pueblo contra sus padecimientos" (Lizondo Borda, 1940, II, pp 293-294). Al año siguiente, un libelo reavivó el debate entre permitir o cercenar la libre expresión. La obra se atribuyó al jesuita Diego León de Villafañe, donde protestaba por la obligatoriedad de inventariar los bienes eclesiásticos y por la ley de libertad de expresión. Consideraba irreligiosas ambas medidas. Mientras este material circulaba, la Sala estaba considerando ciertas reformas que discutían el orden tradicional. (Coviello, 1938, I, p. 3) Las regulaciones a la opinión crecieron en el gobierno de Heredia, que estableció puntillosos decretos contra la libre expresión escrita u oral, como los de 1834 y 1837.

Otro excelente mirador del ensanchamiento de la opinión fueron las primeras experiencias asociativas. Tucumán parecía responder a un clima de época desde su propio laboratorio, en el que se articularon la obra del gobierno, las corrientes reformistas y la acción de las élites letradas. Hacia 1824, Javier López estimuló el surgimiento de una Sociedad Filantrópica, integrada por miembros de la élite de la provincia, en un clima de época en donde en Buenos Aires se iniciaban los preparativos del Congreso de 1824 y crecían las figuras de Martín Rodríguez y Bernardino Rivadavia. En la capital tucumana aparecieron vocablos como progreso, estímulo y fomento, además de una cultura deseosa por impulsar los emergentes espacios de sociabilidad pública. La Sociedad Filantrópica, que existió entre 1824 y 1825, emprendió la recaudación de fondos para restaurar el humilde teatro provincial y para auxiliar a las "clases menesterosas". En sus documentos aparece el concepto de utilidad, pero no necesariamente vinculado a la tradición benthamista. Algunos de sus objetivos 
reaparecerán con mayor entidad en 1850, al crearse la Sociedad de Beneficencia de Tucumán, que tendrá una vida más prolongada y estable, pero la aparición temprana del modelo asociativo en los 20 ' refleja que estas inquietudes estaban ya presentes en la élite tucumana.

Lamadrid no interrumpió este impulso asociativo, pese a ser rival de su antecesor López. Promovió el crecimiento de la esfera pública con iniciativas como la Sociedad de Individuos y el periódico Los Amigos Del Orden. En su gestión, los diálogos permanentes con el Congreso reunido en Buenos Aires y las frecuentes misiones fuera del territorio, conectaron al norte con el proyecto liberal rivadaviano y lo enfrentaron con las expectativas federales de Bustos, Quiroga e Ibarra. En consonancia con esto, Lamadrid incluyó en su gobierno a letrados como el abogado Juan Bautista Paz y el médico Manuel Berdía, este último representante de Tucumán al formarse la Liga del Interior y encargado de las vacunaciones de la población. ${ }^{10}$

Otros guiños a Buenos Aires y al espectro filosófico liberal se advierten en las modificaciones que Lamadrid propone a la reglamentación de la legislatura entre otras iniciativas elocuentes de su compromiso con la facción unitaria en formación. ${ }^{11}$

Con la Sociedad de Individuos (1826), Lamadrid procuró convertir en amigos a quienes se habían molestado por el desplazamiento violento del gobernador López. Se trataba de un ámbito reglamentado de opinión que complementaba a las instituciones de gobierno en su afán por constituir un espacio de discusión de proyectos gubernamentales. La impronta militar de Lamadrid, su torpeza al presidir esta asociación que se suponía de libre discusión y la superposición de sus funciones con la legislatura explican la fugaz existencia de las reuniones de estos 44 vecinos, incorporando a mujeres en su composición. En sus memorias, Lamadrid confiesa que el propósito era brindar a los ciudadanos un espacio para denunciar los actos de gobierno que merecían su reprobación para así "no volcarlos en los cafés", intentando cooptar las disidencias. (Nanni, 2011)

Pese a su precariedad, ensayos como el anterior dan cuenta de la circulación de un ideal de espacio público moderno. El viajero inglés Joseph Andrews alabó los contrapesos del legislativo local, y fue testigo entre 1824 y 1825 del impacto de sus ofrecimientos como agente de la corona británica, entre ellos, la creación de una Sociedad de Estímulo a la Minería. El particular clima político que reinaba en Tucumán a su llegada, mostraba familias dispuestas a reglamentar una posible explotación del cerro Aconquija y ávida por establecer puentes comerciales y culturales con Inglaterra, todo lo cual quedó expresado en reuniones y banquetes a través de brindis hacia la progresista monarquía de Jorge IV. Apoyado en argumentos sobre los beneficios de los adelantos técnicos, Andrews sugirió el abandono de la matriz católico-hispánica a fin de conseguir el progreso tal como él lo entendía. En esta línea, criticó a los diputados religiosos que se oponían a la minería y los responsabilizó de hacer que las mujeres, cuando salían de misa, lo observaran a él como un demonio con cola (Nanni, 2017). A pesar de la estrecha sociabilidad que este inglés guardó con el gobernador López y la notabilidad tucumana, semanas más tarde la legislatura desechó el artículo 12 del tratado con Gran Bretaña referido a la tolerancia de cultos y por ley estableció la exclusividad de la Religión Católica, Apostólica, Romana como antes lo había dispuesto la Constitución de 1820.

Durante los años de Heredia, continuó la habilitación de nuevos saberes y prácticas que buscaban especializarse como medicina, abogacía y otras profesiones liberales. También mantuvo el plan de creación de escuelas de primeras letras iniciado en la década anterior. Creó la Escuela de Música con un estricto reglamento que controlaba a los "aprendices" y reclutó luthiers que reparaban los instrumentos de la banda provincial, aún en los delicados momentos de la guerra contra Bolivia y Perú. Se difundió la vacuna contra la viruela y se implementó un registro oficial de vivos y muertos. El gobernador también fundó la Villa “Alejandrina” en base a argumentos de salud pública como el evitar "miasma pútrido que impregna el aire", donde se fomentó la agricultura siguiendo las nuevas ideas. ${ }^{12}$

El aspecto de la ciudad también se transformó durante estas décadas de autonomía y afianzamiento político, destacándose la labor de Felipe Bertrés. Este ingeniero francés ocupó un cargo de existencia intermitente en la provincia, el de Agrimensor General. Desde allí se ocupó de trazar los planos topográficos 
de la ciudad y reorganizar su planta urbana siguiendo ideas del utilitarismo. Modificó la plaza -para realzarla como centro cívico-, refaccionó el edificio del Cabildo que ahora albergaba al gobernador y a la Sala, y ornamentó el espacio público, especialmente en ocasión de fiesta (Paterlini de Koch, 2009, pp. 277-299 y Ben Altabef, 2011, pp. 253-313). ${ }^{13}$

Durante este tiempo también se creó un Cementerio, en base a discursos de salud e higiene, buscando evitar la costumbre de inhumación en las Iglesias. Los mismos argumentos de cientificidad, racionalidad administrativa y orden se utilizaron para establecer un registro de los abastecedores de carne y la prohibición de matar reses cerca de la ciudad. ${ }^{14}$

Las modificaciones a las Casas Consistoriales, en 1824, estilizaron su antigua estructura colonial con detalles neoclásicos (Coviello, 1938, I, p.63). Esta nueva estética estuvo vinculada al ideal republicano, con creciente expansión en Hispanoamérica. La sección destinada a la Legislatura fue reacondicionada en 1833 para poner al reparo del frío y del calor a los diputados y para albergar mejor al público (Ídem, pp.496-497). En torno a la rediseñada plaza central funcionaron dos cafés, un "teatro" y dos escuelas. Ésta continuó siendo el escenario de fiestas y del mercado, aunque en los veinte ya había planes para su traslado (Andrews, 1967, pp. 70-72; Jaimes Freyre, 2003, 91-98; Parolo, 2008, pp. 194-204).

Las fiestas tuvieron mayor regularidad durante la década de 1820 que en años anteriores. Su financiamiento sostenido y la repetición de los programas festivos las consolidaron como una actividad ordinaria del gobierno a cargo del Departamento de Policía desde la supresión del Cabildo. De esta manera, las celebraciones lograron cierto grado de planificación y lucimiento, aunque no puedan compararse a las de Buenos Aires. ${ }^{15}$

En los festejos, el pueblo soberano alcanzaba visibilidad a partir de la celebración de sus nuevas autoridades, el recuerdo de su participación en la Revolución, de su hermanamiento con las demás provincias y la difusión de los nuevos principios políticos. En la década de 1810, la concurrencia a las nóveles fiestas políticas se obligó bajo pena de multa o cárcel, pero esto desaparece a partir de 1820. Quizás, la anterior recurrencia de amenazas logró internalizar la asistencia; o tal vez el nuevo espíritu republicano no admitía obligar la participación al anular el estímulo a la virtud; o simplemente la gente gustaba ir a los festejos como categóricamente afirman los memoristas y los viajeros.

Desde el inicio de la autonomía provincial, los rituales políticos tendieron a ser más solemnes y a abandonar las "diversiones populares" tan frecuentes durante la colonia. No obstante, el protagonismo de la devoción (misas, procesiones, etc.), del resonar de la música y de los bailes que organizaba la población por la tarde luego de las instancias oficiales de festejo, mantuvieron la base popular de las celebraciones del calendario oficial.

De manera paralela a este desarrollo, los desfiles y paradas militares ganaron la escena. Lo militar vino en ascenso desde el segundo lustro de la década del diez; solo que desde los años veinte, la ciudadanía en armas no sólo rememoraba la Revolución, sino también el poder efectivo del Gobernador. Esto no debe ocultar que, tras la desaparición del Cabildo, la Sala fue la autoridad más honrada por el ritual festivo en los tempranos veinte, en tanto encarnación viva de la soberanía popular. No obstante, conforme avanzó la década, la inestabilidad política impuso otras prioridades a la población. En ese marco, las ceremonias y discursos comenzaron a representar a los gobernadores como figuras del orden que impedirían los enfrentamientos que obstaculizaban el desenvolvimiento de las actividades productivas. Aparecieron como hombres desinteresados del poder que sacrificaban la tranquilidad de su vida privada en pos del bien común. Este conjunto de representaciones fue legada a las administraciones de Heredia y Gutiérrez que las desarrollaron con matices propios. El primero, convocando a la "fusión de los partidos" en un clima de creciente unanimidad y el segundo, introduciendo la liturgia federal rosita en Tucumán(Wilde, 2014). 


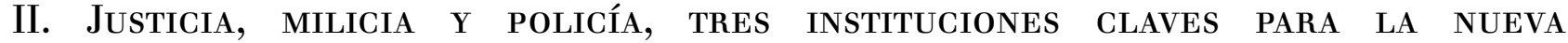 GOBERNABILIDAD}

\section{II.a. ¿Garantizar derechos o mantener el orden?}

En el último tramo del período colonial, el Cabildo buscó monopolizar el ámbito de la justicia local asegurándose los nombramientos de los alcaldes (antes, el gobernador Intendente y el Alcalde Provincial de la Hermandad participaban en estas designaciones). Tomando como base las circunscripciones eclesiásticas, el Cabildo creó tantos partidos políticos-administrativos como curatos y estableció la elección de seis alcaldes anuales, uno por cada partido de la campaña y dos para el curato rectoral (ciudad). Los jueces rurales constituían la baja justicia, mediante los cuales el cuerpo capitular esperaba controlar la campaña "plebeya". En la ciudad actuaban los alcaldes ordinarios. El último recurso era la Audiencia de Buenos Aires. Esta estructura se mantendrá con pocas modificaciones hasta la década de $1830 .^{16}$

La justicia que estos alcaldes aplicaban era de naturaleza estamental, equiparaba delito y pecado y tenía por objeto garantizar el orden jerárquico y corporativo. Las resoluciones dependían principalmente del rango y fama del imputado y de la jerarquía de los testigos en su contra, desde estos datos, el juez aplicaba sentencia según la costumbre (Garriga, 2004).

El gobierno revolucionario central, antes de su colapso, intentó imponer instancias procesuales que garantizaran los derechos individuales. En tal sentido, estableció al Juez de Alzadas -que era uno en cada capital provincial, designado por el Director Supremo- como instancia de apelación de los jueces ordinarios; creó la Cámara de Apelaciones como última instancia en reemplazo de la Audiencia de Buenos Aires y aspiró a la igualdad de todos frente a la ley, la cual debía imperar de manera absoluta por sobre la costumbre y la justicia lega.

Sin embargo, la caída del Directorio en 1820 planteó una retroversión general de las potestades de gobierno en las provincias, entre ellas, la justicia. Las nuevas autoridades provinciales intentaron reorganizar este ramo a pesar de la desaparición de las instancias superiores y seguir el ideal moderno de justicia. Los jueces serían designados por la Legislatura e integrarían una nueva baja justicia que tendría un primer y un segundo recurso de apelación en la Provincia; introdujeron la exigencia de jueces abogados o, en su defecto, de asesorías letradas; mantuvieron la abolición del tormento como parte del proceso judicial (que databa de 1813); prohibieron el juramento del imputado en su confesión -dado que podía implicar la obligación de declarar en su contra-, e introdujeron la nueva figura del padrino -que defendía los derechos del imputado-. Estas reformas buscaban establecer la independencia de los poderes y garantizar los derechos de las partes.

La ley, y no la costumbre ni la jurisprudencia, sería la fuente del sistema jurídico, y su interpretación sería prerrogativa exclusiva del poder legislativo. Esto implicaba el reemplazo de los jueces legos (vecinos probos y/ o con cierta experiencia en la función judicial) por jueces letrados, formados en leyes, que se limitaran a aplicar su texto a todos por igual. Tal era el horizonte que -al menos en la letra- poseyeron las reglamentaciones de los años veinte, sobre todo si se las compara con las precedentes -en las que la noción de individuo no existey las de las décadas del treinta y cuarenta, donde el disciplinamiento de los sectores populares, el orden y el resguardo de la propiedad privada se imponían a cualquier otra garantía.

Tomaron como modelo instrumentos constitucionales pensados para una dimensión nacional, especialmente al Reglamento de 1817. Sin embargo, las provincias tuvieron serios problemas para constituir todas las instancias de apelación dentro de sus fronteras y para imponer el absolutismo legal. La escasez de recursos económicos y humanos, la persistencia de la mentalidad tradicional, la inexistencia de una codificación que reemplazara al entramado legal colonial y el recurso a la jurisprudencia fueron obstáculos insalvables. 
Con todo, al comienzo se intentó vincular la justicia rural a la urbana para que las causas siguieran un proceso más completo y superaran las resoluciones rápidas y domésticas tan frecuentes en el ámbito rural. De este modo se trató de dar cierto resguardo a las garantías individuales. ${ }^{17}$ La sentencia de los jueces ordinarios podía apelarse frente al Juez (o tribunal) de Alzada -según el reglamento que se tome-. Con dos sentencias conformes finalizaba la causa. La apelación a la sentencia de la Alzada se realizaba frente a un Tribunal superior. No obstante, el estudio de las prácticas judiciales revela que los jueces o los tribunales de Alzada tuvieron una existencia variable y que la última instancia rara vez se constituyó. ${ }^{18}$ Tampoco existió ningún oficio de control de los funcionarios o de los pleitos entre ellos, de los que antes se ocupaba la Audiencia.

Los escasos recursos de la provincia impusieron un límite a la voluntad de modernizar la burocracia del estado. La insuficiencia de jueces y de personal auxiliar produjo la acumulación de funciones en un mismo agente; alcaldes y policía terminaron teniendo casi las mismas funciones en la campaña y a veces los comandantes departamentales también hacían de jueces pedáneos. En el Tucumán de los veinte, sólo había un juez territorial cada 5 mil habitantes aproximadamente, mientras en otras provincias como Córdoba, había un juez cada 750 habitantes (Tío Vallejo, 2014). Esto obligaba al juez a recurrir a sus capataces, vecinos y familiares para resolver situaciones en su vasta jurisdicción -hablamos de causas contra subalternos, porque los vecinos recurrían directamente a la justicia urbana-. Lo recién descripto, además de atentar contra el objetivo de racionalización y división de funciones, podría implicar cierta continuidad de la justicia doméstica, sin embargo, los jueces territoriales sólo estaban autorizados a formar cabeza del proceso, no tenían facultades para aplicar ninguna resolución o castigo. Hasta avanzada la década de 1820, las causas de origen rural, incluso las más comunes, se continuaron en la ciudad con la intervención de padrinos, asesores letrados, recursos de apelación y demás elementos orientados a garantizar derechos. Pero estas experiencias tenderán a ser cada vez menos frecuentes.

El exiguo número de abogados limitó las posibilidades de elección para jueces, dificultó la constitución de las instancias de apelación y determinó avances y retrocesos en la exigencia de sentencias con dictamen de letrado y en el requerimiento de este atributo para los jueces de Alzadas. La escasez de letrados llevó a la persistencia de una justicia orientada más al mantenimiento del orden social vigente que a la aplicación de la ley. Tampoco abundaban los vecinos con capacidades para desempeñarse como jueces legos o como conjueces ad hoc en los tribunales, de allí la dificultad para integrar los tribunales de apelación y la necesidad de acortar los procesos aun a costas de las garantías de los ciudadanos.

Hasta 1828, la designación de todos los jueces estuvo a cargo de la Legislatura, lo que vigorizó el objetivo de división de poderes ${ }^{19}$, pero ese año la Sala concedió el nombramiento de jueces al gobernador a causa de las convulsiones políticas. Al año siguiente, autoriza al Ejecutivo a reformar libremente los ramos de la administración pública, entre ellos, la justicia, a la cual subordinó. Desde entonces, no parece que la designación de los jueces haya vuelto a la Sala.

En efecto, el reglamento de 1829 reemplaza las veleidades liberales de comienzo de década por posibilidades reales: la alzada sería de existencia eventual y los dictámenes legos de la justicia ordinaria se harían definitivamente sin asesoría letrada. ${ }^{20}$ El decenio se cierra, además, con un Ejecutivo munido de amplias atribuciones judiciales; además de nombrar jueces, les envía "aconsejamientos” a los alcaldes junto con las acusaciones que le hacían llegar los comisarios y jueces pedáneos. ${ }^{21}$

En las décadas de 1830 y 1840, este pragmatismo se acentuó. Alejandro Heredia y Celedonio Gutiérrez consolidaron la dependencia de la justicia respecto del gobernador y ampliaron las tareas de los jueces a cuestiones que excedían lo judicial. En el discurso del período y en su profusa reglamentación, el interés por las garantías y los derechos individuales cedió ante el encargo de la vigilancia y el disciplinamiento de los sectores populares.

Desde entonces, los decretos ordenaron todos los aspectos de la vida de los habitantes. Además de lo usual -acreditación de empleo, regulación del consumo de alcohol, del juego, del comportamiento en público-, 
las reglamentaciones se expedían sobre el uso del tiempo libre, la conducta privada, la asistencia a misa en días laborables, la vestimenta de los pobres y el modo de circular en las calles. El control de las lealtades y la prevención de insurrecciones se tramitó mediante el control de pasaportes, correspondencia, la prohibición de portación de armas, la regulación de las reuniones, la exigencia de la delación y el endurecimiento de las penas. ${ }^{22}$ Heredia inició esta "fiebre" reglamentarista pero los gobiernos subsiguientes la mantuvieron o aumentaron, todo lo cual implicó la multiplicación de funciones y de agentes en el territorio.

Entre los años 1832 y 1834, Heredia reformó la estructura jurisdiccional que permanecía intacta desde la colonia. Creó dos nuevos partidos, ahora denominados "departamentos" (Graneros y Leales -ex Los Juárez-), sumando un total de 8 jurisdicciones incluyendo la capital. Respecto de la justicia, dispuso que cada departamento tuviera dos jueces (Alcaldes de Hermandad) y un Juez de Alzada, que atendería las apelaciones a las sentencias de los alcaldes de su jurisdicción. La sentencia de esta alzada se ejecutaba sin más recurso. Todo el proceso se llevaba de manera oral, salvo que la parte pidiera sentencia escrita. Las causas ordinarias que se llevaban por escrito debían iniciarse con firma de abogado, lo cual las hacía menos numerosas. ${ }^{23}$

Estas medidas buscaban aliviar la tarea de los juzgados ordinarios haciendo que los pleitos se resolvieran en su departamento de origen mediante proceso rápido y oral. El virtual divorcio de la justicia rural con la urbana se completó con la dependencia de los alcaldes pedáneos respecto del jefe de policía (antes dependían de los jueces urbanos). Para mayor celeridad de la justicia, Heredia facultó a los jueces territoriales a sentenciar en causas de hasta veinticinco pesos y en ciertos delitos o casos estipulados por los reglamentos (cuando antes sólo podían abrir sumario). Además, suprimió a los comisarios (policía rural) y sus funciones fueron absorbidas por los alcaldes de campaña. Como ahora los jueces territoriales reunían tantas tareas (de vigilancia e información, represión, juzgamiento y aplicación de ciertas penas) en distritos que seguían siendo muy amplios, estuvieron autorizados a delegar en otros sus funciones (vecinos allegados, capataces o personal de milicias), práctica que dijimos, fue común en la colonia. Esta justicia territorializada agilizaba los procesos, pero restaba garantías y recuerda a la expeditiva justicia rural del reglamento cordobés de $1823 .^{24}$

La justicia urbana también se simplificó. Heredia eliminó el juzgado del crimen -vigente desde 1825-, y estableció dos jueces que se encargaron indistintamente de lo civil y criminal. No obstante, exigió jueces letrados a cargo de las apelaciones, valiéndose del aumento de abogados en la provincia. Además de las Alzadas, estableció como último recurso la formación (eventual) de un Supremo Tribunal de Justicia cuyo presidente también debía ser letrado. ${ }^{25}$

Durante el interregno entre las gobernaciones federales de Heredia y Gutiérrez (1838-1841), las reglamentaciones hacia los sectores subalternos y la estructura judicial se mantuvieron. ${ }^{26}$ Lo que sí, estos gobiernos, que se consideraban liberales, rehabilitaron los comisarios de campaña y crearon una Cámara de Justicia de carácter permanente en lugar del anterior tribunal eventual de Heredia. ${ }^{27}$

$\mathrm{Al}$ asumir Celedonio Gutiérrez, los comisarios rurales volvieron a ser eliminados, como lo había hecho Heredia y en Buenos Aires, Rosas (Garavaglia, 2009). En consecuencia, los jueces de campaña -como así también los comandantes departamentales- vieron ampliadas sus facultades. El andamiaje reglamentario de Heredia (con nuevas disposiciones contra los “salvajes unitarios” y exigencias de adhesión federal) no sólo continuó vigente, sino que se ajustó para lograr mayor control por parte del ejecutivo. El reglamento de justicia de 1842 contiene por primera vez la mención de que el Gobierno, además de nombrar a todos los jueces, los podía destituir por mal comportamiento. Es decir, la instancia de control de los funcionarios que había desaparecido junto a las Audiencias coloniales- reaparece, pero como atribución que robustece al gobernador. ${ }^{28}$ Además, Gutiérrez declara a sus agentes territoriales personalmente responsables de toda conspiración que pudiera registrarse en sus distritos. Este dispositivo coercitivo se complementaba con la sujeción -en la práctica- de los jueces rurales respecto de los comandantes departamentales, los cuales, a su vez, estaban inmersos en una red de lealtades y subordinación que abordaremos más adelante. 
En el ordenamiento de Gutiérrez ningún juez requería ser letrado, en cambio, aparecen requisitos variables de idoneidad y fortuna que iban en aumento según la instancia de ejercicio. ${ }^{29}$ También se exigía ser federal. La aceptación de los cargos públicos era obligatoria so pena de ser reputado como "salvaje unitario", lo cual tenía graves consecuencias patrimoniales y personales. Otra novedad es la figura del Juez conciliador, agente que mediaba entre las partes intentando solucionar el pleito antes de que llegue a primera instancia. Su intervención era obligatoria en demandas de 25 pesos o más. Como siempre, el objetivo era abreviar los procesos, incluso, evitarlos. ${ }^{30}$ La total subordinación del Poder Judicial al Ejecutivo y su carácter lego constituyeron las soluciones que Gutiérrez opuso al eterno problema de integración de los tribunales, especialmente de los Superiores. En adelante, las apelaciones a las sentencias de las Alzadas fueron resueltas por el propio gobernador, ahora constituido en última instancia. ${ }^{31}$

\section{II.b. La fuerza militar}

Durante la colonia, las milicias no constituyeron una institución política como lo llegaría a ser a partir de la guerra de independencia. En el Antiguo Régimen, este servicio de armas era muy diferente al desempeñado por las fuerzas regulares, que eran rentadas y estaban sometidas a una disciplina muy exigente. La participación en las milicias, en cambio, era expresión del compromiso de los vecinos en la defensa de la patria entendida en clave local y constituía una extensión de sus prerrogativas socio-territoriales. Tenían el encargo de colaborar con el Cabildo en el resguardo del territorio, sus caminos y del orden público de la campaña. Las milicias se integraban con los vecinos de la ciudad y de la campaña de 16 a 45 años y gozaban de la protección del fuero militar. Su organización en distintos cuerpos exclusivos, de acuerdo al rango social del vecino miliciano, otorgaba prestigio a los más encumbrados que, además, en el caso de ser convocados al servicio, podían pagar a personeros para que cumplieran su compromiso. ${ }^{32}$

Con el advenimiento de la guerra revolucionaria y ante el desmantelamiento del aparato burocrático español y el embrionario desarrollo de las instituciones del nuevo orden, las fuerzas militares se transformaron en el cuerpo de funcionarios más importante del Estado y el ámbito con mayores posibilidades de ascenso político para la oficialidad. Las exigencias de la guerra liquidaron el restringido criterio colonial de incorporación al servicio de armas y se comenzó a incluir a todos los "habitantes" de la jurisdicción, ${ }^{33}$ además de enganchar a los "vagos y mal entretenidos", e incluso esclavos a cambio de su libertad tras el servicio. No obstante, la organización interna mantuvo su carácter jerárquico y de servicio eventual, subsistiendo las distinciones entre los regimientos según la calidad socio-ocupacional de sus miembros. Había una tajante diferencia social entre la oficialidad y la tropa, en el sistema de excepciones y en las promociones, que se mantuvieron por lo general dentro del círculo de vecinos.

Por otro lado, si bien el gobierno revolucionario central aspiraba a formar una fuerza veterana centralizada, el marco no lo permitió y fue creciente su dependencia de las milicias locales que negociaban permanentemente con sus autoridades y eran cada vez más activas políticamente. Esta militarización fue la base de los ejércitos provinciales luego del hundimiento del gobierno central a comienzos de 1820. A partir de entonces, las milicias tuvieron un rol político principal. Los vecinos jóvenes que se alistaron y participaron en batallas exitosas durante la década de 1810, fueron los que en la década siguiente encabezaron las luchas facciosas por el poder en la provincia. El ascendiente sobre la tropa, como sostiene Tío Vallejo (2001), fue una de las dos fuentes de legitimidad del poder político tras la Revolución; una variable clave que condicionaba el acceso y la permanencia del gobernador en su cargo. Por tanto, su control era fundamental para la construcción y estabilización institucional del nuevo estado.

En Tucumán, las milicias legadas por el período revolucionario fueron reorganizadas por primera vez por el gobernador Javier López en 1824 y 1825. A diferencia de otras provincias, Tucumán no tuvo ejército de línea, principalmente porque no poseía en aquella época problemas con indígenas en sus fronteras. Pero sí tenía 
una numerosa milicia. López la reformó creando un regimiento de caballería ligera de carácter permanente, cuyas compañías recibirían instrucción militar regular y estarían apostadas en cada uno de los seis partidos que por entonces tenía la provincia. El superior a cargo sería un comandante designado por el gobernador. Este cuerpo se articuló a la milicia de la capital de existencia previa. ${ }^{34}$

Las milicias de campaña eran las de base social más amplia, las de mayor número de efectivos y las de carácter más permanente, por eso López y los gobernadores subsiguientes tendieron a fundar en ellas su apoyo. El ideal de López era una fuerza centralizada en su mando y homogénea en su instrucción. Su éxito fue limitado. Había al menos dos graves problemas; la provincia carecía del personal idóneo suficiente para reemplazar por completo a la jefatura militar anterior (la vencida por la nueva facción política actualmente en el poder), lo que hubiera dado mayores garantías de su fidelidad y, por otro lado, el reclutamiento también se reveló como un factor desestabilizador. Los criterios de vecindad para acceder al enrolamiento continuaron flexibilizándose, López sólo exigió la calidad de hombres "honrados y libre de vicios". Esta definición tan ambigua fue un poderoso recurso en manos del gobernador que afectaba a individuos y familias por el reclutamiento, como así también a poderosos propietarios que perdían trabajadores (a veces en castigo por haber apoyado a la facción enemiga). Por tanto, no fue raro que los reclutamientos terminaran en nuevos movimientos de fuerza en contra del gobierno, muchas veces capitaneados por jefes opositores que no pudieron ser reemplazados. Los mandatarios podían negociar hasta cierto punto la obediencia de sus jefes militares y éstos, la de sus subalternos, a través de la distribución de ciertos incentivos: cuotas de poder, ascensos, retribuciones económicas, reconocimientos y premios que otorgaban prestigio y honor, etc. Pero en la década de 1820 esas variables fueron de muy difícil gestión, por lo que las lealtades militares se mantuvieron volátiles.

Heredia (1831-1838) desarrolló el esquema de compañías departamentales iniciado por López y lo convirtió -según Macías (2014)-, en la clave de su estabilidad política. Estabilidad que le permitió consolidar las reformas institucionales que se habían iniciado en la década de 1820 e introducir otras nuevas con vistas a crear el Estado provincial. Ni bien accedió al gobierno, Heredia aumentó la cantidad de partidos en la campaña y dotó a cada uno de ellos con un regimiento a cargo de un comandante de su elección -excepto Graneros y Río Chico que tenían un regimiento entre ambos-. ${ }^{35}$ En 1836 se ocupó de la milicia urbana. Intentó mantener su carga simbólica notabiliar y cívica, intentando que los requisitos de su integración coincidieran con los del sufragio, salvo la edad, porque se votaba a partir de los 21 años y las milicias podían integrarse desde los $15 .{ }^{36}$ El objetivo de Heredia era articular estos cuerpos -que resumían a la élite urbanaal sistema de lealtades militares que ya había creado en la campaña.

Los comandantes fueron la pieza clave de la nueva organización militar. Como ellos eran quienes protagonizaban los movimientos armados contra los gobernadores, Heredia aseguró su dependencia y lealtad ampliando sus atribuciones. Estos jefes, además de encargarse del enrolamiento, se ocuparon de la captura de desertores y traidores al gobierno, de emitir pasaportes, controlar el juego, el alcoholismo, el conchabo y de participar en las mesas electorales. También tuvieron algunas funciones judiciales similares a los jueces pedáneos y al de policía (captura de reos, elaboración del sumario y ejecución de penas dispuestas por jueces o por ellos mismos en los casos habilitados por los decretos del gobernador). La comandancia no era rentada, su atractivo provenía de las cuotas de poder y de los beneficios que reportaba este vínculo con el gobernador. $\mathrm{Si}$ a esto se suma que, en general, el perfil social de los comandantes solía ser modesto y casi siempre inferior al de los jueces locales, podemos concluir que el cargo también implicaba más prestigio a su titular. Además, el fuero les brindaba cierta inmunidad y gran potestad sobre sus subordinados, aunque su contracara fuera la propia sujeción al gobernador, cúspide del escalafón. ${ }^{37}$

¿Qué obtenía Heredia de esta estructura de fuerza? la difusión de las prácticas electorales y la movilización de electores para su renovación en el cargo; el control de la campaña para prevenir conspiraciones, el poder garantizar seguridad y mano de obra a los propietarios allanando con esto el progreso de la élite y su cooptación. Con la sujeción de las milicias, la preeminencia sobre los jueces y la dependencia de la 
policía, el gobernador proyectaba su autoridad en el territorio provincial y la reafirmaba entre sus agentes porque los conflictos entre ellos -que eran bastante usuales por la similitud de funciones y jurisdicciones-, lo posicionaban como árbitro máximo, permitiendo al mandatario la reevaluación de las lealtades y la redistribución de su respaldo y aprobación.

El sistema reveló su potencia aún después del asesinato de Heredia. La nueva élite gobernante no logró la anuencia de los comandantes de campaña y, para peor, se había atraído la guerra contra Rosas por su participación en la Coalición del Norte (1840-1841). ${ }^{38}$ Frente a esta emergencia, no tuvieron más alternativa que ampliar el enrolamiento de la milicia urbana exigiendo sólo el domicilio. Por primera vez, no fueron las distinciones tradicionales o la ambigua calidad de "hombre decente" las que marcaron el ingreso a las fuerzas cívicas, sino meramente el lugar de residencia, a semejanza del alistamiento rural.

La Coalición fue derrotada en septiembre de 1841 y Celedonio Gutiérrez fue proclamado gobernador de Tucumán. Su primer tiempo de gestión, como ocurrió con todos los gobiernos que asumían tras la derrota de una facción enemiga, estuvo signado por prácticas fuertemente coactivas, aunque en el caso de Gutiérrez ese período se extendió por poco más de dos años y fue especialmente intolerante. En el orden de lo discursivo y lo simbólico, aquel estado de guerra fue permanente y resultó funcional al objetivo de fortalecimiento y centralización del poder en su persona.

En el plano militar, no sólo aumentó los regimientos departamentales, ${ }^{39}$ sino que transformó todo el servicio de armas en servicio regular. Antes, sólo los regimientos de la campaña lo eran. Como los opositores que sucedieron a Heredia encontraron apoyo en la milicia urbana, Gutiérrez quiso prevenir esto convirtiendo a los cuerpos cívicos en fuerzas permanentes totalmente subordinadas al sistema de lealtades que convergía en el gobernador y del cual ya participaban las milicias departamentales. ${ }^{40}$

Los comandantes seguían siendo la clave de esta fuerza; Gutiérrez incrementó aún más sus funciones con el argumento de la constante acción de los "salvajes unitarios". Además de las amplias competencias otrora entregadas por Heredia, estos jefes también levantaban inventarios y ejecutaban confiscaciones de bienes de los identificados como unitarios; informaban, delataban y capturaban a sospechosos de unitarismo entre la población rural; celaban el desempeño de jueces, policías y sacerdotes de su jurisdicción. Proponían anualmente a los vecinos "capaces" y "claramente Federales" para los cargos civiles de su departamento; seleccionaban a los aspirantes a la Escolta del Gobernador y requisaban ganado, armas y dinero de los vecinos para el sustento de las tropas -función que compartían con jueces y auxiliares de policía-. Además, mediaban entre los "buenos federales" de su jurisdicción y el gobernador por pedidos de exoneración de impuestos, obtención de algún favor personal o eximición de prisión por causas leves. Esta constelación de atribuciones se otorgaba de manera informal, dado que no figuran en ninguna reglamentación militar, por tanto, constituía un poderoso capital a distribuir discrecionalmente por Gutiérrez.

La gran cuota de poder conferida por el gobernador a sus comandantes cimentó un sistema recíproco de lealtades mucho más compacto que el que logró Heredia porque combinó la jerarquía militar fuertemente atada al fuero con una inédita extensión del enrolamiento, lo que hacía que casi toda la población masculina activa estuviera penetraba por la lógica marcial (Parolo, 2010).

\section{II.c. La policía}

El tercer componente del poder territorial del gobernador fue la Policía. Durante la colonia, ésta fue una de las funciones del antiguo cabildo, orientada al orden público, la seguridad y el abastecimiento del campo y la ciudad. A partir de la Revolución, este ramo se ocupó también del proceso electoral, del reclutamiento militar y de las requisas para aprovisionar a las tropas. Desde 1820, el Gobernador asumió la dirección de esta sección, que más tarde se reorganizó como Departamento de Policía, en 1826. A partir de entonces, el Juez de policía contó con comisarios que cumplían funciones de policía en la campaña teniendo -cada 
uno de ellos-, entre cuatro a seis hombres a su cargo. El principio rector fue separar la baja justicia de la policía, pero la insuficiencia de recursos económicos y la escasez de agentes civiles hizo que los comisarios continuasen desempeñando funciones judiciales de instrucción. Además, en la ciudad, el Juez de policía se encargaba de ejecutar las disposiciones de gobierno referidas a las celebraciones públicas, muy importantes para la representación simbólica del nuevo orden y su legitimación. ${ }^{41}$

Como apuntamos antes, Heredia eliminó a los comisarios y derivó sus funciones a los comandantes y jueces de campaña. Estos últimos quedaron vinculados al juez general de policía institucionalizando la confusión de funciones que las reglamentaciones de los años veinte -con aires liberales- habían intentado vanamente evitar. Los sucesores de Heredia restituyeron a los comisarios, pero luego Gutiérrez los volvió a eliminar. No obstante, este mandatario reintegró al Departamento de Policía el amplio espectro de deberes que este ramo tuvo durante la colonia y la primera década revolucionaria, a las cuales sumó la vigilancia y captura de todo sospechoso de unitarismo y la prevención y represión de todo movimiento de fuerza contra el gobierno. Por último, la policía de Gutiérrez poseyó más atribuciones judiciales que cualquiera de sus pares anteriores; el jefe de policía podía levantar sumarios y resolver sentencias en los casos de robo y ebriedad aplicando penas de hasta quinientos azotes y multas de hasta 20 pesos. ${ }^{42}$ Esto último apuntaba a abreviar los procesos orientados al disciplinamiento ejemplar de los sectores populares.

\section{Conclusión}

A lo largo de estas páginas pudimos observar cómo la élite dirigente gestionó el gobierno bajo el nuevo paradigma de la soberanía popular, ajustando la herencia colonial a los nuevos horizontes ideológicos y a las condiciones y límites geopolíticos posrevolucionarios. En este sentido, vimos cómo a partir de insumos de tipo constitucional, pensados para una jurisdicción extra local, se intentó dar solución a la ingeniería institucional que exigía el nuevo principio de legitimidad política y la construcción del orden republicano.

El momento previo a la organización nacional fue un período de transición con marcadas continuidades de la cultura política, social y jurisdiccional de la Colonia, pero también de innovaciones. Aparecieron nuevos modos de sociabilidad y participación políticas; surgieron novedades en el discurso y en las representaciones públicas del orden social e institucional y se crearon nuevas instituciones a partir del desmantelamiento de otras de antigua raigambre .

$\mathrm{Al}$ ver en conjunto el proceso de formación de la Legislatura; la evolución del Gobernador y la de las instituciones de Justicia, Milicia y Policía, podemos señalar diferencias entre la década de 1820 y los subsiguientes años hasta 1853. El horizonte liberal del primer momento contrasta con el creciente afán de control social e institucional que se observa en las décadas de 1830 y 1840 a partir del fortalecimiento de las potestades del Ejecutivo. Si bien este último fenómeno se inicia a finales de los veinte, su consolidación durante los períodos de Heredia y Gutiérrez modificaron el funcionamiento que habían tenido los diputados, los agentes de justicia, la policía y las milicias.

Mientras que en los años 1824 a 1827 hubo un especial fomento gubernamental a la prensa, a las asociaciones y a otras formas de sociabilidad política y de opinión pública -como lo fueron las tertulias semiprivadas de la élite o las fiestas cívicas-religiosas y el debate legislativo en la Sala-; en las décadas del treinta y cuarenta estos espacios desaparecieron o se transformaron bajo la política absoluta de la unanimidad. Por ejemplo, el Boletín Oficial de Heredia -que sólo publicaba las obras de gobierno- o el periodismo federal de Gutiérrez difieren notablemente de la prensa oficialista de Bernabé Aráoz, en la que había espacio para las cartas de los lectores y los posicionamientos políticos eran menos excluyentes.

En el ámbito de la justicia se observa una evolución institucional similar. En el texto de las disposiciones de la década de 1820 se intenta adecuar los principios de libertad, seguridad e igualdad civil del Reglamento de 1817 a la organización de la justicia de la provincia, pero estos esfuerzos naufragaron frente a las señaladas dificultades estructurales y coyunturales que atentaron contra una justicia moderna e independiente y 
coadyuvaron a la concentración de poder en el Ejecutivo. Como en la colonia, la justicia siguió siendo un ámbito dominado por los vecinos que intervienen para restaurar un orden social que consideraban natural; caracterizado por las jerarquías tradicionales y el poder normativo de la religión. La administración de justicia ostentó poca igualdad y escaso texto de la ley. Su peso represivo se descargó contra los opositores del gobierno de turno y hacia los delitos perpetrados contra las actividades y propiedades de la notabilidad.

El avance del gobernador en el ramo de Justicia se instrumentó a través de medidas específicas como la elección de los jueces por parte del Ejecutivo o su constitución como última instancia judicial a semejanza del viejo Intendente borbónico, pero también a partir de la territorialización de las Alzadas y la dependencia de los jueces pedáneos respecto de la milicia y la policía (cuando antes, los jueces rurales respondían a la justicia ordinaria urbana). Esta conformación -que se dio desde los treinta-, institucionalizó las atribuciones judiciales de los comandantes departamentales y del Jefe de policía, quienes estaban directamente subordinados al Gobernador.

Las milicias también se territorializaron y aumentaron su enrolamiento, lo cual otorgó al Gobernador una extensa red de agentes en la campaña que se sumaron a los de justicia en su tarea de disciplinamiento social de los sectores populares y de vigilancia y hostigamiento a los opositores políticos. De esta forma, Heredia y Gutiérrez tuvieron el monopolio casi total de la fuerza a partir de la cual pudieron no sólo fiscalizar hasta cierto punto la unanimidad política, sino ofrecer seguridad, conchabos y prosperidad a los principales a cambio de su apoyo.

Las reformas en las milicias también redundaron en una extensión de la ciudadanía política. La flexibilización de los criterios de enrolamiento en situación de pleno derecho (y no como pena judicial en "vagos y malentretenidos") amplió el concepto de vecindad en vista de las necesidades de la guerra y de la militarización de la política, produciendo una creciente identificación entre el miliciano de libre enrolamiento y los ciudadanos habilitados para emitir el voto según la ley electoral de 1826, vigente hasta mediados de siglo. Además de esto, los milicianos también participaron de la política como autoridades del proceso electoral o protagonistas de pronunciamientos armados. Por esta razón, los jefes militares fueron elementos clave de la gobernabilidad del territorio provincial. En este sentido, las reformas del período tendieron a penetrar el tejido social con las milicias y a centralizar en el gobernador la lealtad y obediencia de sus comandantes. A este fin obedeció la expansión del carácter permanente del servicio de milicias, la difusión de la instrucción regular, la continuidad del fuero, el aumento de las atribuciones de los comandantes y la departamentalización de la estructura militar que tuvo -como vimos- su reflejo complementario en la ruralización de la justicia.

En este desarrollo, Gutiérrez representa el cénit de la concentración del poder de la República en la figura del Ejecutivo. Su Sala estuvo reducida a la convalidación de sus requerimientos y a su renovación canónica en el poder con facultades extraordinarias, las cuales desdibujan el sentido mismo de la presencia institucional de la Legislatura. Igualmente, la Sala se mantuvo y renovó según los términos de la ley, sosteniendo la legitimidad del régimen. La justicia del período de Gutiérrez fue preponderantemente lega, verbal y expeditiva; resolvía casi todas las causas en su lugar de origen y sus agentes fueron todos designados por el gobernador. Estos jueces compartían -y competían- funciones con los comandantes que, por jerarquía marcial, dependían del favor del primer mandatario. Esto se suma a la expansión del servicio regular de armas, del reclutamiento y, por tanto, de la población masculina sujeta al fuero militar. No solo las autoridades intermedias estuvieron subordinadas al gobernador, sino también sacerdotes y vecinos que actuaron como agentes represores, testigos y acusadores contra los inferiores.

La ascendencia que el gobernador-militar obtuvo sobre la Legislatura, la Justicia y las fuerzas del orden (milicia y policía) le otorgó al Ejecutivo un creciente control sobre la población, pero esto no lo exceptuó de conflictos. La escasa "modernización” o delimitación de funciones, jurisdicciones y la acumulación de cargos en una misma persona generalizaron las rencillas entre las autoridades intermedias, aunque, como observamos, la mayoría de las veces estas pujas coadyuvaron a fortalecer el rol y la autoridad del gobernador. 
Por otra parte, la estabilidad y el orden social ganados parecían mantener a gran parte de la élite satisfecha, al menos mientras duró la pax rosista en la Confederación.

La evolución local de las instituciones de corte republicano ubicó al gobernador a la cabeza de todos estos ordenamientos de los cuales monopolizaba todas sus designaciones. Esto le permitió sembrar el territorio con sus delegados dando una respuesta concreta a los problemas de gestión del poder que habían desestabilizado recurrentemente a la política. Este fue el modo en que se logró la continuidad y el arraigo de las instituciones y los procedimientos de representación de la República. Una república, como dijimos al inicio, de base popular amplia y de carácter autoritario antes que liberal. Una república que, en situación de indefinida emergencia, concentraba en el gobernador gran parte del poder y priorizaba el orden común a los derechos y garantías individuales.

\section{REFERENCIAS}

Abbate, G. (2017). Representación y opinión en la construcción del orden politico a partir de la Revolución de Mayo. Tucumán, en las primeras décadas del siglo XIX [Tesis doctoral]. Universidad Nacional de Tucumán, San Miguel de Tucumán, Argentina.

Andrews, J. (1967). Las provincias del Norte en 1825. San Miguel de Tucumán, Argentina: Universidad Nacional de Tucumán.

Coviello, A. (Ed.). (1938). Actas de la Sala de Representantes, I (1823-1835) y II (1836-1853). Tucumán-Buenos Aires: Universidad Nacional de Tucumán - Instituto de Historia, Lingüística y folklore.

Ben Altabef, N. (2011). Educar en Tucumán en la primera mitad del siglo XIX. El modelo pedagógico colonial y el nuevo modelo educativo. Permanencias e iniciativas. En G. Tío Vallejo (coord.), La república extraordinaria. Tucumán en la primera mitad del siglo XIX (pp. 253-313). Rosario: Prohistoria Ediciones.

Bravo, M. C. y Ferullo, D. (2017). Las constituciones tucumanas en la segunda mitad del siglo XIX. Entre la contingencia y la construcción de un orden político. En: M. Bonaud (coord.), Representaciones de la politica.Provincias, territorios y municipios (1860-1955). Rosario: Imago Mundi.

Celesia, E. H. (1930). Constitución de la República del Tucumán año 1820. Buenos Aires: Ed. Julio Suárez.

Chiaramonte, J. C. (1995). ¿Provincias o Estados?: Los orígenes del federalismo rioplatense. En: François-Xavier Guerra (dir.), Revoluciones Hispánicas. Independencias americanas y liberalismo español. Madrid: Complutense.

Davio, M. (2018). Morir por la Patria. Participación y militarización de los sectores populares en Tucumán, 1812-1854. Rosario: Prohistoria Ediciones.

Garavaglia, J. C. (2009). La cruz, la vara, la espada. Las relaciones de poder en el pueblo de Areco. En: D. Barriera (comp), Justicias y fronteras. Estudios sobre historia de la justicia en el Rio de la Plata. Siglos XVI-XIX (pp.89-117). Murcia: Editum.

Garriga, C. (2004). Orden jurídico y poder político en el Antiguo Régimen. Revista de Historia Internacional, 4(16). Disponible en: http://ffyll.uncu.edu.ar/IMG/pdf/Garriga.pdf

Jaimes Freyre, R. (2003). Historia de la República de Tucumán. San Miguel de Tucumán: Universidad Nacional de Tucumán.

Lizondo Borda, M. (1940). Documentos Tucumanos. Actas del Cabildo (1817-1824) (Vol. II). Tucumán.

Macías, F. (2014). Armas y politica en la Argentina. Tucumán, siglo XIX. España: Consejo Superior de Investigaciones Científicas.

Macías, F. y Parolo, M. P. (2010).Guerra de independencia y reordenamiento social. La militarización en el norte argentino (primera mitad del siglo XIX). Iberoamericana. América Latina - España - Portugal, 10(37), 19-38.

Munilla, M. L. (2013). Celebrar y gobernar: un estudio de las fiestas cívicas en Buenos Aires, 1810-1835. Buenos Aires: Miño y Dávila Ed. 
Nanni, F. (2011). Sesiones, interrupciones y debates. La Sala de Representantes de Tucumán en sus inicios (1822-1838). En: G. Tío Vallejo (Comp.), La República extraordinaria. Tucumán en la primera mitad del siglo XIX. Rosario: Prohistoria.

Nanni, F. (2013). Ese bullicioso grito de un rumor, que de boca en boca aumenta su vuelo. Alejandro Heredia frente al crecimiento de las voces de oposición, Tucumán (1832-1838). Revista Páginas, 5(9).

Nanni, F. (2016). El primer periódico tucumano. Bernabé Aráoz y la reutilización de la antigua imprenta belgraniana. En Americanía. Revista de Estudios Latinoamericanos (pp. 308-344). Sevilla: Universidad Pablo de Olavide.

Nanni, F. (2017). Tras las huellas de George Lefebvre. Tucumán en las guerras de independencia. Rumores alarmistas, noticias falsas y temores compartidos. Revista Nuevo Mundo-Mundos Nuevos. https://doi.org/10.4000/nuevo mundo.71423.

Parolo, M. P. (2008). Ni súplicas ni ruegos las estrategias de subsistencia de los sectorespopulares en Tucumán en la primera mitad del siglo XIX. Rosario: Prohistoria.

Parolo, M. P. (2010). Entre jueces y comandantes. Formas de autoridad en la campaña tucumana a mediados del siglo XIX. En: D. Barriera (coord.), La Justicia y las formas de la autoridad Organización politica y justicias locales en territorios de frontera. (El Rio de la Plata, siglos XVII-XIX) (pp. 107-127). Rosario: ISHIR-CONICET- Red Columnaria.

Paterlini de Koch, O. (2009). Felipe Bertres, ingeniero francés, constructor de ciudad y territorio. En N. B. Robledo et al. Ramón Leoni Pinto. In memoriam (pp.227-299). Tucumán: Centro Cultural Alberto Rougés, INIHLEPUNT,

Tau, A. V.y Martiré, E. (2005). Manual de historia de las Instituciones Argentinas. Buenos Aires: Librería y Editorial Histórica.

Terán, J.B. (1910). Tucumán y el Norte Argentino (1820-1840). Buenos Aires: Imprenta de Coni Hermanos.

Ternavasio, M. (2004). Construir poder y dividir poderes. Buenos Aires durante la "feliz experiencia" rivadaviana. Boletin del Instituto de Historia Argentina y Americana "Dr. Emilio Ravignani”, (26), 7-43.

Tío Vallejo, G. (2001). Antiguo Régimen y Liberalismo. Tucumán, 1770-1830. Tucumán: Facultad de Fil. y Letras de la UNT.

Tío Vallejo, G. (2008). La administración de justicia y la experiencia de las autonomías provinciales en el Río de la Plata. El caso de Tucumán. Revista de Historia del Derecho, (36), 365-398.

Tío Vallejo, G. (2011). Una justicia de vecinos en la "república armada" Tucumán, 1820-1852. En: C. A. Piazzi (coord.), Modos de hacer justicia: agentes, normas y prácticas: Buenos Aires, Tucumán y Santa Fe durante el siglo $X I X$, (1a ed., pp. 25-44). Rosario: Prohistoria Ediciones.

Tío Vallejo, G. (2014). Vecindad y territorio en la construcción de lo político entre el antiguo régimen colonial y la construcción de un orden republicano. En: Y. Celaya (coord.), Diálogos con una trayectoria intelectual: Marcello Carmagnani. México: El Colegio de México.

Wilde, A. (2014). Celebrar la regeneración de la república. La liturgia política en Tucumán durante la primera mitad del siglo XIX [Tesis doctoral inédita]. Universidad Torcuato Di Tella, Buenos Aires, Argentina.

Zamora, R. (2019). Tradiciones jurídicas y pervivencias económicas en la genealogía constitucional. El caso de Tucumán en 1820. Derecho, (82), 61-91.

\section{Abreviaturas DE FUENTES INÉDITAS E IMPRESAS}

AHT: Archivo Histórico de la Provincia de Tucumán - Se citan las secciones:

AL: Archivo de la Legislatura (Documentación existente en el AHT)

SA: Sección Administrativa.

OV: Oficios Varios (Sección Administrativa del AHT) 
TR: Sección Toma de Razón (Fondo de Hacienda del AHT)

MLB, GH: Documentos Argentinos. Gobierno de Alejandro Heredia (Su acción en Tucumán, en las provincias del Norte y en la guerra con Bolivia), 1832-1838. (UNT, Tucumán, 1939).

RO: Registro Oficial. Se citan las raras y salteadas ediciones de esta publicación, correspondientes a años de los gobiernos de Gregorio Aráoz de La Madrid (1826) y de Alejandro Heredia (1834-1837). Documentación existente en el AHT.

\section{Notas}

1 Para un análisis de la Constitución de 1820 consultar Tío Vallejo (2001) y Zamora (2019)

2 "La elección de esta corte se hacía sobre la base de un censo de principales enviado por cada ciudad-pueblo miembro de la república” (Tío Vallejo, 2001).

3 Reglamento Provisorio para la Dirección y Administración del Estado de 1817 (en línea) consultado Septiembre 2020 http://www.cervantesvirtual.com/obra-visor/reglamento-provisorio-para-la-direccion-y-administracion-del-esta do-de-1817/html

4 "Habiéndose tomado en consideración que el cuerpo Municipal era insignificante y sin objeto a quien consagrar sus funciones por haberse el gobierno reasumido, la alta y la baja Policía (...) se sancionó su extinción” (Coviello, 1938, tomo I, pp. 77-78). Lo que esta ausencia de razones muestra es que a los diputados les resultó natural el abandono de este cuerpo, ¿para qué tener una institución electiva aparte si "la baja y alta Policía” la reúnen el gobernador y la sala?, Cfr. Tío Vallejo, 2014.

5 Las causas de la extinción de los Cabildos rioplatenses -en lugar de su reconversión en órganos municipales, por ejemplo, como ocurrió en otros espacios como México-, forma parte de un debate entre reconocidos autores que está lejos de cerrarse. Podemos ver parte de este en Tío Vallejo, 2014.

6 Las referidas disposiciones eran las Normas provenientes de las Cortes peninsulares (1810); el Reglamento de 1811, la circular de octubre de 1812 y el Estatuto de 1815.

7 Un intercambio entre el ministro Paz y el diputado de origen religioso, Pedro Miguel Aráoz, muestra la tensa relación y delimitación entre los poderes. Paz denunció en el recinto la existencia de diputados con "negocios particulares con Buenos Aires" y, como el sacerdote sintió que "se refería a su persona”, contestó entre gritos y argumentos. Frente a esto, el Ejecutivo defendió a su ministro y la legislatura, al diputado, sosteniendo que "no había excedido los límites de la libertad que goza como representante" (Coviello, 1938, I, pp. 150-151)

825 de Octubre de 1824 (AHT, SA, OV, T. 21, f. 20v-21).

9 En sus fundamentos, la ley de 1824 no refiere al antecedente bernabeísta de 1820, pero sí al Reglamento de 1817 (Coviello, 1938, I, pp. 61-62).

10 Sobre vacunaciones (AHT, SA, T. 29, f. 147). Es interesante la forma en la que el médico Manuel Berdia incorporaba principios como el equilibrio de poderes y otras nociones de corte claramente liberal (AHT, SA, T. 32, f. 252: agosto de 1826)

11 En noviembre de 1823 la Sala dio su primer reglamento, que modificó en Diciembre de 1824, para luego con Lamadrid basarse en el reglamento de Buenos Aires (AHT, SA, T. 30, f. 380). Las diferentes versiones de reglamentos tucumanos tenían en común considerar a la Legislatura depositaria de la soberanía, además de garantizar la inviolabilidad de las opiniones de los diputados.

12 Decretos: Sobre la vacuna contra la viruela (AHT, SA, T. 41, f. 422-424); sobre el registro de vivos y muertos (9 de noviembre de 1833: MLB, GH, p. 48-49); creación de Villa Alejandrina (10 de julio de 1832: AHT, SA, T. 41, f. 83-84); creación de la escuela de música (27 de julio de 1832: AHT, SA, T. 41, f. 85v-86v) y Orden sobre reparación de instrumentos (26 de enero de 1838: AHT, SA, OV, T. 40, f. 272).

13 Bertrés nació y estudió en Francia. Arribó a Buenos Aires en 1807 y participó de su defensa frente a los ingleses. En 1814 se incorporó al Ejército Auxiliar del Perú, radicándose en Tucumán donde reconstruyó y finalizó La Ciudadela(fortificación ordenada por San Martín). Las autoridades tucumanas le otorgaron mercedes de tierra, lo designaron Agrimensor General (desde 1820 a 1822 y entre 1826 y 1832) y Director de Escuela (Lizondo Borda, 1940 , II, p. 225: año 1820); DECRETO. 5 de septiembre de 1826: Agrimensor General de la Provincia: AHT, SA, T. 32, f. 294).

1422 de octubre de 1826 (AHT, SA, T. 32, f. 32).

15 En 1827, Tucumán destinó 600 pesos al rubro "culto y fiestas" (Coviello, 1938, I, p. 339: 23 de enero de 1827). Buenos Aires, en 1823, 8.100 pesos; y en 1829 erogó casi 22 mil pesos sólo en las Fiestas Mayas (Munilla, 2013). Aunque la 
provincia tuviera a un profesional de la talla de Bertrés -de capacidad similar a un Próspero Catelin o a un Carlo Zucchi-, su margen de acción fue limitado.

16 La sección sobre justicia es tributaria de los trabajos de Tío Vallejo: 2001, 2008 y 2011 y Parolo, 2010.

17 Se aumentaron los jueces de campaña y se delimitaron claramente sus funciones; éstos y los de Barrio (los alcaldes de la capital) debían limitarse a abrir el sumario al detenido, tomando su confesión y la declaración a los testigos. Luego, el reo era remitido a los Jueces Ordinarios (generalmente había dos) que residían en la ciudad, donde se continuaba el proceso. Allí, la "ciudadanía" (desde 1825) contaba con un funcionario que reunía en sí las funciones tradicionales del Síndico Personero del Común y de Defensor General de Menores y Pobres, como tal, presentaba causas de interés común de los vecinos y actuaba en defensa del reo cuando éste no tenía a quién designar como padrino. (Coviello, 1938, I, p. 32: 9 de diciembre de 1823; pp. 143-145: 12 de enero de 1825; y pp. 308-310: 14 de septiembre de 1826)

18 Desde 1826, sólo las causas de 200 pesos o más llevarían proceso escrito, y sólo las de 100 pesos o más podían apelar la sentencia de la alzada frente a un Tribunal superior que, meses después, fue eliminado por su difícil constitución. Todo esto restó garantías a los más pobres que abundaban en causas de menor valor. El objetivo de estas medidas fue resolver el mayor número de demandas posible en la baja justicia y juzgados ordinarios, que eran las instancias más estables de la provincia.

19 El Juez de Alzada, aun antes de 1828, a veces fue designado por el Ejecutivo, siguiendo al Reglamento de 1817.

20 DECRETO: 2 de junio de 1829 (AHT, SA, T. 32, f. 383v-386)

21 Hay ejemplos de esta intermediación del gobernador en los Borradores de Gobierno de 1829 (AHT).

22 Se podía detener a alguien por muchas razones como, por ejemplo, decir obscenidades en el mercado (Decreto: 14 de febrero de 1832: AHT, SA, T. 41, f. 67v-69).

23 Decretos de 6 de febrero de 1832 (AHT, SA, T. 41, f. 64-65); 11 de febrero de 1832 (AHT, SA, T. 41, f. 66v-67v); 12 de enero de 1833 (AHT, SA, T. 41, f. 98 v-100); 28 de enero de 1833 (AHT, SA, T. 41, f. 104-104v) y de 8 de febrero de 1832 (AHT, SA, T. 41, f. 65v-66v). Los Departamentos eran: Trancas, Burruyacu, Monteros, Leales o Juárez, Chicligasta, Río Chico, Graneros y la Capital.

24 Un juez pedáneo cordobés, constituido en tribunal junto a dos vecinos, podía aplicar penas de hasta 200 azotes a un reo sorprendido infraganti.

25 Leyes: 25 de enero de 1834 (RO, 1834, No 3, p. 4) y 12 de febrero de 1834 (RO, 1834, No 3, pp. 6-8).

26 Las penas incluso se endurecieron para los casos de robo y asesinato: LEY. 6 de marzo de 1839 (AHT, AL, Caja 2, Legajo 137)

27 Decretos de 22 de abril de 1839 (AHT, SA, OV, T. 39, f. 110-110v) y 9 de septiembre de 1839 (AHT, SA, T. 54, f. 240). LEY. 18 de marzo de 1840 (Coviello, 1938, II, pp. 97-99). La Cámara estuvo integrada por tres letrados designados por el gobierno.

28 El reglamento contemplaba diversos castigos según la falta cometida y prevé su amplia publicidad: Reglamento de Justicia de 12 de enero de 1842 (AHT, AL, 1843, caja 3, legajo 192, f. 29-35v)

29 La desaparición del requisito de ser abogado y la mención de eventuales asesorías letradas de fuera de la Provincia seguramente respondió al exilio político de muchos hombres de leyes, cfr. Tío Vallejo, 2011.

30 En 1851, el Reglamento de Justicia de 1842 fue ligeramente modificado y sancionado por la Sala, en esta versión, la territorialidad de la justicia se reforzó al elevar de 25 a 50 pesos las causas a resolver por los jueces de distrito y, por lo mismo, desaparece el juez conciliador. DECRETO: 2 de enero de 1851 (Museo Histórico Provincial "Presidente Avellaneda”, Colección Miguel Alfredo Nougués, carpeta B, documento 67)

31 Si en el proceso no se habían alcanzado dos sentencias conformes, intervenía el gobernador pidiendo informe detallado a la Alzada correspondiente y un escrito a cada una de las partes, con esto, elevaba el último fallo. Pero, en el Reglamento de 1851, Gutiérrez dejó de tener esta potestad al restablecerse un Tribunal superior semejante al creado por Heredia.

32 Esta sección es tributaria de los trabajos de Macías, 2014; Tío Vallejo, 2001 y 2011; Macías y Parolo, 2010; Parolo, 2010 y Davio, 2018.

33 "Habitante" es el hombre domiciliado en la provincia y por ello debía servir en armas, pero esto no implicaba ningún tipo de derecho político ni status social.

34 Leyes: 22 de diciembre de 1824 (AHT, SA, T. 30, f. 393 v) y 22 de noviembre de 1825 (Coviello, 1938, I, p. 215).

35 Decretos: 14 de junio de 1832 (AHT, SA, T. 41, f. 81-81v) y 5 de febrero de 1832 (AHT, SA, T. 41, f. 62-62v)

$36 \mathrm{La}$ incorporación de estos jóvenes al electorado se discutió durante el tratamiento del proyecto constitucional en 1835 que la guerra contra Salta truncó. Por otro lado, la distinción de las milicias urbanas quedó resguardadas por las disposiciones sobre sus uniformes y en la diferenciación social de su integración: comerciantes e hijos de comerciantes -y todo "hombre decente"- para la infantería y hacendados e hijos de hacendados para la caballería: DECRETO. 7 de noviembre de 1836 (AHT, SA, T. 46, f. 24-24v)

37 DECRETO. 29 de julio de 1833 (AHT, SA, T. 41, f. 112v-113v) 
38 Para atraer a los antiguos jefes de Heredia (y con ellos a sus tropas) se aumentaron sueldos y perdonaron deudas, entre otras concesiones, pero sin éxito. Comandantes rurales como Gutiérrez y Mendevil defeccionaron uniéndose a las fuerzas federales invasoras y esto determinó la derrota final de la Coalición del Norte (Macías, 2014).

39 Creó el departamento de Famaillá en 1843 y llevó de 7 a 10 el número de regimientos en la provincia.

40 Se creó el Batallón de Federales de la Guardia Tucumana y la nueva Escolta del Gobernador, fuerzas cívicas de servicio permanente y de instrucción militar regular, que además participaban de los festejos públicos ostentando el poderío militar efectivo del gobernador en cada conmemoración (Macías, 2014 y Wilde, 2014).

41 Decretos: 21 de julio de 1824 (AHT, TR, T. 3, f. 335); 10 de marzo de 1824 (AHT, TR, T. 3, f. 295); 16 de septiembre de 1826 (AHT, SA, T. 32, f. 473) y 21 de septiembre de 1826 (AHT, SA, T. 32, f. 402). LEY del 23 de enero de 1827 (Coviello, 1938, I, p. 337-341). Esta síntesis sobre la Policía es tributaria de los trabajos de Tío Vallejo, 2001 y 2011 ; Macías, 2014 y Parolo, 2010.

42 ORGANIZACIÓN POLICIAL. 11 de mayo de 1842 (AHT, AL, 1843, caja 3, legajo 192, f. 37v-44) 